doi:10.12662/2359-618xregea.v5i2.p47-63.2016

\title{
ARTIGOS
}

\section{ASSOCIAÇÃO DE MULHERES LOUCEIRAS DO MARUANUM (ALOMA): TRADIÇÃO E ECONOMIA SOLIDÁRIA NO ESTADO DO AMAPÁ - AMAZÔNIA -BRASIL}

\section{RESUMO}

A economia solidária vem se fortalecendo e se afirmando como uma possibilidade viável, sensata e emancipadora. Nesta perspectiva, este artigo tem como objetivo analisar a Associação de Mulheres Louceiras do Maruanum (ALOMA), localizada no extremo norte da Amazônia Brasileira, Estado do Amapá, de forma a evidenciar os principais avanços e fragilidades na política de fomento à economia solidária, assim como os principais progressos e entraves enfrentados pela Associação. Realizou-se estudo de caso sobre a ALOMA, com Análise de Custo-Efetividade (ACE), por meio de entrevistas com a presidente da Associação e com outras associadas, concretizando uma pesquisa qualitativa. Encontra-se estruturado em três partes; a primeira tratou da política nacional de economia solidária e suas as estratégias de fomento aos empreendimentos; a segunda apresentou o espaço geográfico da pesquisa, o Estado do Amapá; e a última parte analisou a Associação, seu perfil, principais resultados das políticas de fomento e seus principais entraves e avanços.

Palavras-chave: Economia solidária. Política Pública. Associa-

Kátia Paulino dos Santos katiapaulinoap@yahoo.com.br Doutora em Gestão pela Universidade de Trás-os-Montes e Alto Douro de Portugal - UTAD (2017), Mestre em Planejamento e Políticas Públicas pela Universidade Estadual do Ceará - UECE (2010), Especialista em Politicas Públicas de Emprego, Trabalho e Renda pela Universidade Estadual de Campinas UNICAMP (2006) e Bacharel e Licenciada em Ciências Sociais pela Universidade Federal do Amapá - UNIFAP (2005). Professora da Universidade do Estado do Amapá (UEAP) Macapá $-A P-B R$. ção de Mulheres Louceiras do Maruanum.

\section{INTRODUÇÃO}

Os reflexos da exploração do homem pelo homem se intensificam e afirmam como regra de vivência no modelo capitalista. Esta realidade possui consequências políticas, econômicas e sociais diversas, as quais ultrapassam em muito as tendências de análises que focam na dualidade dicotômica limitada entre o bem o mal. Em meio a este contexto, em que a criatividade, a inovação, a busca pela satisfação do cliente e a concorrência são características fundamentais, emerge uma proposta com características bem diferenciadas do empreendedorismo tradicional, a economia solidária, que traz como missão a promessa de aliar geração de renda à solidariedade, gerando fortes expectativas de se tornar uma opção às mazelas econômicas e sociais vivenciados no cenário caótico do capitalismo.

A economia solidária insere-se em um contexto comple- 
xo e dinâmico, uma vez que surge como uma possibilidade diferenciada, dentro de um modelo econômico com fragilidades expostas, e que tenta inviabilizar qualquer tentativa de alteração de sua lógica. As constantes crises e desestruturações demonstradas pela economia capitalista impulsionam cada vez mais a busca por alternativas, seja por parte da sociedade civil organizada, seja por parte do Estado.

A economia solidária avança no Brasil em diferentes perspectivas. Do ponto de vista social, percebe-se um crescimento referente à quantidade de empreendimentos que compõem o setor; verifica-se, ainda, a pulverização do esclarecimento referente ao contexto teórico e ideológico em que estes empreendimentos estão inseridos, uma vez que muitos se encontravam dentro da proposta de economia solidária sem saber exatamente seu significado e as diferenças de nuanças, em comparação com a economia capitalista tradicional. Na perspectiva econômica, os indicadores revelados pelo último mapeamento dos empreendimentos da economia solidária, realizado nas diferentes regiões e estados brasileiros, que teve início em 2010 e foi finalizado em 2013, demonstram que a proposta tem sido responsável pela elevação da renda e, consequentemente, das condições econômicas dos empreendedores que compõem a economia solidária no Brasil.

Além disso, verificou-se na última década uma intensificação significativa das políticas públicas de fomento à economia solidária, fortalecidas pela criação da Secretaria Nacional de Economia Solidária (SENAES), em 2003. A institucionalização da SENAES, aliada ao delineamento de uma política concentrada em ações pautadas em pesquisas empíricas, geraram credibilidade e reconhecimento social da Instituição.

A proposta da economia solidária tem sido fomentada em diferentes regiões e estados brasileiros, entre eles o Amapá, localizado no extremo Norte do Brasil, área de estudo deste artigo. Destacam-se, entretanto, as especificidades deste Estado, cuja cultura do empreendedorismo encontra-se ainda em pro- cesso de solidificação, em função da trajetória histórica diferenciada, influência e reflexos do baixo povoamento, que integra a realidade do cenário amazônico.

Analisou-se neste artigo a Associação de Mulheres Louceiras do Maruanum (ALOMA), empreendimento econômico solidário do Estado do Amapá, composto por mulheres que trabalham com um tradicional artesanato em argila, que é reconhecido popularmente pela valorização cultural da comunidade do Maruanum. A confecção do artesanato segue um ritual marcado por simbolismos tradicionais, que são repassados de geração em geração. Representa um importante mecanismo de renda para as mulheres associadas, considerando que o empreendimento é composto por mulheres de baixa renda, como a maioria das pessoas residentes na comunidade do Maruanum.

Objetivou-se com este estudo compreender os principais avanços e fragilidades da ALOMA, assim como os impactos das políticas de fomento à economia solidária ofertadas pelo Estado à Associação. Para tanto, realizou-se pesquisa qualitativa, por meio de estudo de caso, tendo como objeto a Associação. Buscou-se evidenciar os resultados alcançados pela Associação por meio de abordagem que ultrapassa o aspecto meramente econômico, levando em consideração, também, os fatores sociais de desenvolvimento. Realizaram-se entrevistas com a presidente da Associação e com outras associadas. Foi realizada ainda visita in loco para verificar as instalações da Associação, bem como as condições de trabalho das associadas.

Para fins didáticos, este artigo foi estruturado em três partes, além da introdução e das considerações finais de praxe. A primeira tratou da origem e conceitos da economia solidária, bem como da gestão nacional da política e das estratégias de fomento aos empreendimentos. A segunda parte apresentou o espaço geográfico da pesquisa, o Estado do Amapá, enfatizando-se as características socioeconômicas da população, do mercado de trabalho e as potencialidades econômicas. E, por fim, analisaram-se os 
resultados do estudo de caso da ALOMA, revelando-se seu perfil, os resultados centrais das políticas de fomento e seus principais entraves e avanços para seu desenvolvimento.

\section{ECONOMIA SOLIDÁRIA: ORI- GEM, CONCEITOS E GESTÃO DA POLÍTICA PÚBLICA DE ECONO- MIA SOLIDÁRIA NO BRASIL}

Esta seção contempla o arcabouço teórico acerca da origem e conceitos da economia solidária, bem como das suas estratégias de gestão como política pública de desenvolvimento no cenário brasileiro.

\subsection{ECONOMIA SOLIDÁRIA: ORIGEM E CONCEITOS}

Ao tratar da origem da Economia Solidária, Lechat (2002) enfatiza que na Inglaterra e nos Estados Unidos várias comunidades ou aldeias cooperativas foram criadas no século XIX, mas não conseguiram manter-se por mais de alguns anos, as numerosas experiências de cooperativas operárias lideradas pelo movimento sindical inglês, após vários êxitos e avanços democráticos, foram extintas pela feroz reação da classe patronal e pela declarada hostilidade do governo. As iniciativas de grupos associativos solidários eram incipientes no mundo, sendo progressivamente intensificadas após as duas grandes guerras mundiais, e massificadas após a crise econômica mundial iniciada no final da década de 1970.

Lechat (2002) enfatiza ainda que entre 1980 e 1985 foram criadas em massa cooperativas de trabalhadores em toda a Europa. Por outro lado, os inúmeros movimentos sociais e étnicos trouxeram uma nova visão do social, de sua relação com o econômico e da relação do homem com o meio ambiente. Diante deste cenário, são fortalecidos na década de 1980 estudos e publicações voltados para a análise da economia solidária, os quais apresentam percepções e conceituações variadas.

Dentro do quadro de estudiosos, destaca- -se Paul Singer, reconhecido pela densa produção teórica direcionada ao tema e que foi titular da Secretaria Nacional de Economia Solidária do Brasil (SENAES) por 13 anos. Singer (2008) considera que a Economia Solidária é um modo de produção que se caracteriza pela igualdade. Pela igualdade de direitos, os meios de produção são de posse coletiva dos que trabalham com eles - essa é a característica central. E a autogestão, ou seja, os empreendimentos de economia solidária são geridos pelos próprios trabalhadores coletivamente de forma inteiramente democrática, quer dizer, cada sócio, cada membro do empreendimento tem direito a um voto. Caso sejam pequenas cooperativas, não há nenhuma distinção importante de funções, todo mundo faz o que precisa.

França Filho (2002) ressalta que, com a noção de economia solidária, a questão que se coloca é aquela de um novo relacionamento entre economia e sociedade. Se certas características organizacionais particulares (notadamente no que se refere ao aspecto democrático da organização do trabalho) são sublinhadas na apreensão desse termo, trata-se aqui, entretanto, sobretudo da inscrição sociopolítica das experiências que fundam essa noção. Esta é a razão pela qual se entende que, para além de um conceito servindo para a identificação de um certo número de experiências com um estatuto diferente daquele da empresa capitalista, a noção de economia solidária remete a uma perspectiva de regulação, colocada como uma questão de escolha de um projeto político de sociedade.

Gaiger (2007) enfatiza que o crescimento da economia solidária no Brasil tem sido um fato notável nas últimas décadas, relatado em estudos panorâmicos e confirmado pelo primeiro mapeamento: 87\% dos Empreendimentos Econômicos Solidários (EES) registrados tiveram início posterior a 1990, 35\% após 2002. Ao mesmo tempo, a articulação gradativa dos empreendimentos e das organizações de apoio resultou em estruturas representativas da economia solidária, culminando com a criação do Fórum Brasileiro de Economia Solidária, em 2003. 


\subsection{A SECRETARIA NACIONAL DE ECONOMIA SOLIDÁRIA (SENA- ES)}

O ano de 2003 representou um importante marco referente à política de fomento e valorização da economia solidária no Brasil com criação da SENAES, e, consequentemente, da dinamização das ações delineadas pelo estado brasileiro à economia solidária, que passam a congregar um complexo de políticas públicas que ganham destaque em todas as regiões brasileiras. De acordo com Singer (2006, p. 201):

A economia solidária começa a desenvolver-se vigorosamente no Brasil a partir da última década do século passado. Está em sua origem o renascimento dos movimentos sociais, no ocaso do regime militar, que se prolongou até 1985. Estes movimentos foram colhidos pela imensa crise social, desencadeada por políticas neoliberais de abertura do mercado interno às importações, de juros elevados e ausência de desenvolvimento, este último sacrificado no altar da estabilidade dos preços. Do ponto de vista do desenvolvimento, as duas últimas décadas do século $\mathrm{XX}$, para o Brasil, foram perdidas, o que acarretou desemprego em massa, fechamento de empresas e redução da produção e do emprego. Calcula-se em milhões o número de postos de trabalho eliminados.

A SENAES é vinculada ao Ministério do Trabalho e Emprego (MTE), funcionando dentro das instalações do Ministério, ocupa o menor espaço físico entre as outras secretarias que vinculadas e ainda conta com um número pouco significativo de funcionários do quadro. A SENAES é formada por Gabinete, Departamentos e Coordenações que, articulados, executam o conjunto de competências da Secretaria.

No ano de 2009 investiu consideráveis recursos para a realização de Cursos de Formação em Economia Solidária, na qual se objetivava esclarecer a temática para empreendedores identificados como solidários, para representantes governamentais (prefeituras e estados) e para a sociedade civil organizada. Passada essa etapa de "esclarecimento", no ano de 2010 a SENAES passou a outra importante etapa de fomento à economia solidária, o mapeamento de empreendimentos identificados como econômico-solidários, a fim de se mensurar não só a quantidade desses empreendimentos, mas a dimensão desta "economia alternativa" no Brasil. (SECRETARIA NACIONAL DE ECONOMIA SOLIDÁRIA, 2012).

De acordo com um relatório da Secretaria Nacional de Economia Solidária (2012), o público-alvo das políticas públicas em ES os cidadãos que estejam organizados ou queiram se organizar nas formas da Economia Popular Solidária. A prioridade de acesso volta-se aos cidadãos que vivem em situação de maior vulnerabilidade social, particularmente aqueles beneficiados por programas de transferência de renda e de geração de trabalho e renda. Nesse sentido, torna-se fundamental reconhecer a diversidade de sujeitos deste setor e adequar a cada um as formas de acesso e trânsito dentro da política.

Com a criação da SENAES, foi possível implantar um conjunto de ações que visam ao fomento e fortalecimento das iniciativas de ES, enquanto formas de organização do trabalho associado. Internamente, no Ministério do Trabalho e Emprego, a discussão sobre a ES enfrentou resistências, já que a vocação histórica deste órgão era tratar das questões dos trabalhadores/as assalariados/as. Contudo, com o passar dos anos, a SENAES consolidou-se, contribuindo para ampliar a missão institucional do Ministério no fomento ao trabalho associado ao lado de outras formas de trabalho assalariado.

\subsection{O SISTEMA DE INFORMAÇÕES EM ECONOMIA SOLIDÁRIA (SIES)}

O Sistema de Informações em Economia Solidária (SIES) foi desenvolvido pela Secretaria Nacional de Economia Solidária, sob a coordenação da Comissão Gestora Nacional e em parceria com o Fórum Brasileiro de Eco- 
nomia Solidária, sendo um instrumento para identificação e registro de informações de empreendimentos econômicos solidários, entidades de apoio e fomento à economia solidária e políticas públicas de economia solidária no Brasil. (SECRETARIA NACIONAL DE ECONOMIA SOLIDÁRIA, 2013).

Destaca-se como pesquisa de economia solidária tanto por ser pioneira em consolidar uma base de dados de abrangência nacional, quanto por seu modelo de gestão participativa da pesquisa. Embora a base seja muito nova e só tenha chegado à metade dos municípios brasileiros (e com limites), é preciso reconhecê-la como importante avanço para o dimensionamento da economia solidária em todo o território brasileiro. Nas demais bases nacionais, como as do Instituto Brasileiro de Geografia e Estatística (IBGE), não existem categorias específicas como "trabalhador associado", "sócio cooperado", "empresa autogestora" e, por isso, é impossível identificar com precisão o que constitui economia solidária em meio aos dados globais. (SANTOS, 2014).

O SIES foi implantado no ano de 2004 e, até o momento, realizou três rodadas nacionais de identificação e caracterização dos Empreendimentos Econômico-Solidários (EES) no país. O primeiro levantamento ocorreu em 2005 quando foram mapeados 14.954 EES. Este levantamento foi complementado em 2007 com o mapeamento de mais 6.905 EES. Nesta primeira fase foram totalizadas informações de 21.859 EES. A terceira rodada ocorreu nos anos de 2010-2012 quando foram mapeados mais 11.663 EES. Portanto, desde 2004 o SIES já identificou 33.518 EES em todo o território nacional. (SECRETARIA NACIONAL DE ECONOMIA SOLIDÁRIA, 2013).

Os dados do SIES demonstram que $72,7 \%$ dos empreendimentos receberam apoio ou assessoria externa, sendo que $40,6 \%$ de órgãos governamentais, $22,9 \%$ de ONGs, Igrejas ou associações, $20,4 \%$ do "sistema S", etc. Segundo Gaiger (2009, p. 576), os "EES beneficiados com algum apoio apresentam um grau de desempenho global mais positivo do que os demais, exceto no caso de EES apoiados unicamente por órgãos governamentais". Não há dúvida de que o envolvimento dos agentes externos qualifica o processo; a questão é sobre o espaço de decisão que estes agentes adquirem frente aos EES em seu cotidiano e em um plano maior - no FBES.

O Mapeamento das experiências de Economia Popular Solidária consistiu em uma das atividades realizadas pela SENAES e pelo Programa de Economia Solidária em Desenvolvimento, que abrangeu mesmo com a incipiência do programa, todos os estados brasileiros. Este mapeamento procurou desvelar as principais características socioeconômicas dos empreendimentos coletivos de geração de trabalho e renda no Brasil, relacionadas com as seguintes indagações: Qual é a renda obtida por estas experiências? Onde estão localizadas? Qual a quantidade existente de experiências coletivas? Quantos trabalhadores estão inseridos, entre outros elementos? Para que o mencionado programa social possa contribuir para a viabilidade das experiências coletivas, possibilitando a manutenção e permanência destes empreendimentos no mercado, de forma que passem a obter sobras e consequentemente gerar renda para seus trabalhadores, faz-se necessário uma apreensão desta realidade. (GOERCK, 2009).

Singer (2012) destaca que o mapeamento é uma forma sistemática de entender o que está acontecendo com relação à economia solidária no País. Mas é preciso, a cada três ou quatro anos, ver tudo o que está acontecendo, sobretudo avaliando o que está sendo feito. Verifica-se que o fomento aos empreendimentos da economia solidária deve percorrer um ciclo planejado e estratégico, em que a linha de chegada ou finalização seja concomitante ao processo de emancipação do empreendimento, para que não se estabeleça um elo de dependência ou subordinação ao Estado ou a agentes públicos. 


\section{O ESTADO DO AMAPÁ-AMAZÔ- NIA-BRASIL: CARACTERÍSTICAS SOCIOECONÔMICAS E MERCA- DO DE TRABALHO}

A Região Norte compreende quase a metade da área territorial do Brasil, possuindo a maior extensão, que é dividida entre sete estados, abriga a maior floresta tropical do mundo, a Amazônica, e entre as densas matas e os grandes rios uma imensidão cultural e étnica é celebrada. Neste capítulo serão analisadas as características da população e do mercado de trabalho do extremo norte do Brasil, o Estado do Amapá, com vistas a viabilizar a compreensão dos mecanismos organização e da realidade socioeconômica diante do cenário nacional em que está inserido. do Tumucumaque) e a noroeste com o Suriname (pela Serra do Tumucumaque). Possui $1.691 \mathrm{~km}$ de fronteira nacional e $707 \mathrm{~km}$ de estrangeira. É atravessado pela linha do Equador, sendo que sua área representa $3,71 \%$ da Região Norte e $1,68 \%$ da área nacional (PORTO, 2003, p. 21).

Segundo ainda as informações do Instituto Brasileiro de Geografia e Estatística (2014), a renda média per capita mensal no Estado do Amapá, que possui uma densidade demográfica de 4,69 habitantes por quilômetro quadrado, é de R $\$ 753,00$ (setecentos e cinquenta e três reais). De acordo com as informações do Censo/IBGE, o Amapá foi detentor do maior crescimento demográfico do País na última década, conforme demonstrado pela tabela a seguir:

Tabela 1 - Crescimento demográfico - Amapá - Norte - Brasil (2000-2010)

\begin{tabular}{c|c|c|c}
\hline & $\begin{array}{c}\text { População em } \\
\mathbf{2 0 0 0}\end{array}$ & $\begin{array}{c}\text { População em } \\
\mathbf{2 0 1 0}\end{array}$ & $\begin{array}{c}\text { Crescimento (\%) } \\
\mathbf{2 0 0 0 - 2 0 1 0}\end{array}$ \\
\hline Brasil & 169.799 .170 & 190.732 .694 & 12,33 \\
\hline Região Norte & 12.900 .704 & 15.865 .678 & 22,98 \\
\hline Amapá & 477.032 & 668.689 & 40,18 \\
\hline
\end{tabular}

Fonte: Instituto Brasileiro de Geografia e Estatística (2010).

\subsection{POPULAÇÃO E EVOLUÇÃO ECO- NÔMICA}

O Amapá possui uma população estimada (INSTITUTO BRASILEIRO DE GEOGRAFIA E ESTATÍSTICA, 2014) de 750.912 habitantes, distribuídos em 16 municípios, que somados equivalem a uma área de 143.453,7 $\mathrm{Km}^{2}$, representando $3,70 \%$ da Região Norte e $1,67 \%$ de todo o território brasileiro. As cidades com maior número populacional no Estado são Macapá (Capital), com população estimada em 446.757 habitantes, Santana, com 110.565 e Laranjal do Jari, com 44.777.

Situado na Amazônia Oriental, o Amapá limita-se ao sul (pelo rio Amazonas) e a oeste (pelo rio Jarí) com o Estado do Pará, a leste com o Oceano Atlântico, ao Norte com a Guiana Francesa (pelo rio Oiapoque e Serra
A População Economicamente Ativa - PEA$^{1}$ do Estado do Amapá (INSTITUTO BRASILEIRO DE GEOGRAFIA E ESTATÍSTICA, 2010) foi estimada em 258.000 pessoas, sendo a população ocupada do Estado do Amapá composta por 248.000 pessoas e a taxa de população desocupada é de $13,1 \%$, superior à média nacional (8,3\%). A taxa de desocupação, no Amapá, foi estimada em $9,6 \%$ no $1^{\circ}$ trimestre de 2015 , a segunda maior taxa entre as Unidades da Federação, no período; Entre as unidades da federação, Rio Grande do Norte teve a maior taxa $(11,5 \%)$ e Santa Catarina, a menor (3,9\%). A população ocupada foi estimada em 302 mil, refletindo variação de $-2,3 \%$ na comparação com o trimestre anterior e $2 \%$ frente ao mesmo trimestre de 2014 . No $1^{\circ}$ trimestre de 
2015, 77,4\% dos empregados no setor privado tinham carteira de trabalho assinada, apresentando avanço de 1,4 ponto percentual em relação a igual trimestre de 2014 (75,9\%). Em relação ao trimestre anterior, não houve variação estatisticamente significativa. -se que os reflexos da pobreza são revelados na precariedade das moradias, e ainda na elevação dos indicadores de violência urbana.

Tabela 2 - Evolução do IDH - Amapá - Norte - Brasil (1991-2000-2010)

\begin{tabular}{l|c|c|c}
\hline Área de referência & $\mathbf{1 9 9 1}$ & $\mathbf{2 0 0 0}$ & $\mathbf{2 0 1 0}$ \\
\hline Amapá & 0,472 & 0,577 & 0,708 \\
\hline Região Norte & 0,421 & 0,541 & 0,683 \\
\hline Brasil & 0,493 & 0,612 & 0,727 \\
\hline
\end{tabular}

Fonte: Instituto Brasileiro de Geografia e Estatística (2010).

A população do Estado do Amapá tem crescido significativamente, com grandes reflexos na realidade de mercado, conforme será tratado no tópico a seguir.

\subsection{MERCADO DE TRABALHO E PO- TENCIALIDADES ECONÔMICAS}

O mercado de trabalho do Estado do Amapá tem no setor serviços o principal gerador de empregos, fato que se atribui à escassez de polos industriais, sendo que durante várias décadas grande da parte população ocupada estava inserida em empregos e funções públicos. A indústria e a construção civil apresentam resultados modestos, mas vêm apresentando resultados crescentes nas contratações em face das vagas abertas no mercado. A seguir, na tabela 3, será apresentada uma tabela sintética com os indicadores de desenvolvimento amapaense, em comparação com os indicadores nacional e da Região Norte, de acordo com informações do Departamento Intersindical de Estatística e Estudos Socioeconômicos (2011).

O Censo/IBGE (INSTITUTO BRASILEIRO DE GEOGRAFIA E ESTATÍSTICA, 2010) indicou que o quantitativo da população em situação de pobreza no Estado do Amapá é preocupante, apontando o percentual de $12 \%$, bem maior que a brasileira $(8,5 \%)$, sendo inferior à média da Região Norte (15\%) e Nordeste (18\%). Ressalta-
Tabela 3 - Indicadores de desenvolvimento - Brasil, Norte e Amapá - 2009 (em 1000 pessoas)

\begin{tabular}{|l|c|c|c|}
\hline \multicolumn{1}{|c|}{ Indicador } & Brasil & Norte & Amapá \\
\hline $\begin{array}{l}\text { População em } \\
\text { Idade Ativa (PIA) }\end{array}$ & 162.807 & 12.422 & 504 \\
\hline $\begin{array}{l}\text { População } \\
\text { economicamente } \\
\text { ativa (PEA) }\end{array}$ & 101.110 & 7.536 & 285 \\
\hline $\begin{array}{l}\text { Estimativa de } \\
\text { ocupados }\end{array}$ & 92.689 & 6.889 & 248 \\
\hline $\begin{array}{l}\text { Taxa de } \\
\text { desocupação }\end{array}$ & $8,3 \%$ & $8,6 \%$ & 13,1 \\
\hline $\begin{array}{l}\text { Número de } \\
\text { empregos formais }\end{array}$ & 44.068 .355 & 2.408 .182 & 108.191 \\
\hline
\end{tabular}

Fonte: Departamento Intersindical de Estatística e Estudos Socioeconômicos (2011).

Dentro do setor terciário, encontra-se o serviço público o qual, de acordo com o Censo IBGE (INSTITUTO BRASILEIRO DE GEOGRAFIA E ESTATÍSTICA, 2010), representa um percentual de $87 \%$ do PIB do Estado (deste percentual, $45 \%$ refere-se ao serviço público), $9 \%$ do PIB amapaense volta-se para o setor secundário e 4\% para o setor primário. Este indicador demonstra a realidade econômica do Estado, comprovando que o setor público é responsável pela geração de uma fatia significativa dos empregos. Tal fato é entendido por econo- 
mistas e outros especialistas no assunto como um desperdício das potencialidades econômicas existentes no Amapá que, com uma biodiversidade sui generis e ainda uma localização geográfica significativamente privilegiada e estratégica apresenta uma grande possibilidade de crescimento econômico que impactaria, por certo, na realidade social da população, cuja concentração de renda nas mãos de poucos é uma grande marca histórica.

\section{METODOLOGIA DA PESQUISA}

A metodologia deste estudo possui dois focos:

a) apresenta caráter exploratório, uma vez que busca proporcionar maior familiaridade com o problema da investigação, com vistas a torná-lo mais explícito, envolvendo: levantamento bibliográfico, entrevistas com pessoas que tiveram experiências práticas com o problema pesquisado, e análise de exemplos que estimulem a compreensão (GIL, 2008);

a) possui ainda caráter explicativo, uma vez que se preocupa em identificar os fatores que determinam ou que contribuem para a ocorrência dos fenômenos (GIL, 2008).

No segundo ponto, ressalta-se que a presente pesquisa visa compreender os resultados da economia solidária na realidade cotidiana das integrantes da Associação de Mulheres Louceiras do Maruanum (ALOMA), e ainda analisar os resultados da política de fomento à economia solidária realizada pelos órgãos do Estado.

Para se verificar os impactos da atividade para a realidade das empreendedoras foi realizado estudo de caso da Associação, na expectativa de evidenciar os avanços e fragilidades da política voltada ao fomento da economia solidária, a qual ultrapassa a análise meramente econômica, levando em consideração também os aspectos sociais de desenvolvimento.
ARAÚJO (2008) revela que estudo de caso é uma abordagem metodológica de investigação especialmente adequada quando procuramos compreender, explorar ou descrever acontecimentos e contextos complexos, nos quais estão simultaneamente envolvidos diversos fatores.

A pesquisa possui caráter qualitativo que, de acordo com Minayo (2001), trabalha com o universo de significados, motivos, aspirações, crenças, valores e atitudes, o que corresponde a um espaço mais profundo das relações, dos processos e dos fenômenos que não podem ser reduzidos à operacionalização de variáveis. A pesquisa qualitativa é criticada por seu empirismo, pela subjetividade e pelo envolvimento emocional do pesquisador, mas certamente viabiliza de forma mais concreta a decodificação de uma realidade que não pode ser mensurada estatisticamente, a exemplo da pesquisa do porte do estudo de caso. A pesquisa qualitativa preocupa-se, portanto, com aspectos da realidade que não podem ser quantificados, centrando-se na compreensão e explicação da dinâmica das relações sociais.

Optou-se pela utilização de entrevista não-estruturadas. Estas modalidades de entrevistas viabilizam liberdade ao pesquisador, para ir além das respostas, de uma maneira que pareceria prejudicial para as metas de padronização e comparabilidade. Neste método, o entrevistador pode buscar tanto o esclarecimento quanto a elaboração das respostas dadas, pode registrar informação qualitativa sobre o tópico em questão (MAY, 2004).

A entrevista possui uma importância significativa no estudo de caso pois, por meio dela, o investigador percebe a forma como os sujeitos interpretam as suas vivências já que ela "é utilizada para recolher dados descritivos na linguagem do próprio sujeito, permitindo ao investigador desenvolver intuitivamente uma ideia sobre a maneira como os sujeitos interpretam aspectos do mundo" (BOGDAN; BIKLEN, 1994, p. 134).

O objeto de investigação do estudo de caso é a ALOMA, associação localizada no Distrito do Maruanum, localizado na zona rural de Macapá. 
Entrevistou-se a presidente da ALOMA, que tem a idade de 58 anos, e ainda quatro associadas, que trabalham como artesãs há mais de duas décadas com o artesanato, atualmente a ALOMA possui um total 12 de mulheres associadas. As entrevistas foram realizadas na Comunidade do Maruanum, no mês de abril de 2015.

\section{ASSOCIAÇÃO DE MULHERES LOU- CEIRAS DO MARUANUM (ALOMA): TRADIÇÃO, ARTE E ECONOMIA SOLIDÁRIA NO ESTADO DO AMA- PÁ-AMAZÔNIA-BRASIL}

Esta seção apresenta as informações alcançadas pelo estudo de caso, por meio da técnica de observação in loco, análise documental e realização de entrevistas.

\subsection{A COMUNIDADE DO MARUANUM}

O Distrito do Maruanum integra a cidade de Macapá, capital do Estado do Amapá, sendo uma Comunidade composta por mais de dez Vilas, ou Comunidades, distribuídas ao longo do Rio Maruanum. A maior Comunidade é a de Nossa Senhora do Carmo, considerada a sede do Distrito, localizada a $68 \mathrm{Km}$ da cidade de Macapá. A Comunidade possui uma Associação de Moradores que atende aos interesses comunitários, com vistas ao desenvolvimento e implementação de ações concretas para a região (MAFRA, 2003).

A população é composta por descendentes de indígenas, que ali habitavam no passado, e por descendentes de negros em situação de escravidão, trazidos ao Estado no Séc. XVIII para a construção da Fortaleza de São José de Macapá; os negros fugiam em decorrência de maus-tratos, buscando refugiar-se em terras longínquas. De acordo com Mafra (2003, p. 83):

As manifestações culturais e religiosas vividas pelos moradores das comunidades são basicamente advindas das tradições indígenas e africanas. Entre elas, mediante relatos dos mo- radores da região, a Lenda da Mãe do Barro é de grande importância para a comunidade e também para o ritual de confecção da cerâmica Maruanum. A festa religiosa de maior importância para a comunidade é a de Nossa Senhora do Carmo realizada sempre no mês de julho. As danças do Marabaixo e do Batuque também representa uma prática secular em termos de tradições de origem africana e indígena.

O Marabaixo e o Batuque são importantes expressões culturais, não apenas para a Comunidade do Maruanum, mas para todo o Estado do Amapá. O Marabaixo é considerado uma tradição secular; passa de geração em geração ao longo dos anos. É dançado na capital, Macapá, nos meses de maio, junho e julho. O traje dos homens é camisa branca com bordados, calça branca, chapéu de palha enfeitado com fitas e sandálias de couro, enquanto o traje das mulheres é composto de camisa de renda, saia estampada e rendada, anáguas, arranjos naturais na cabeça (flores) e calçadas com sandálias de couro (AMAPÁ, 2013).

As atividades desenvolvidas pela população do Maruanum envolvem homens e mulheres, em uma coletividade singular para a região. Existe cooperação mútua para a realização de atividades do cotidiano, tais como pesca, lavoura e o preparo das festas religiosas. Como atividade exclusiva, destaca-se a confecção da cerâmica, exercida somente por mulheres. De acordo com alguns relatos, esta realidade se deve à falta de interesse dos homens, embora tenham conhecimento de que, tratando-se de uma prática de origem secular, no início do povoamento, as cerâmicas, principalmente as maiores como fornos e alguidares eram também trabalhadas por homens, prática que foi perdida devido aos trabalhos na agricultura e na pecuária (MAFRA, 2003).

\subsection{AS LOUCEIRAS DO MARUANUM E SEUS COSTUMES TRADICIONAIS}

As louceiras moram em locais diversificados, ao longo do Rio Maruanum; algumas, 
inclusive, moram na capital amapaense, cidade de Macapá. O saber das louceiras é repassado de geração em geração. A atividade é específica para mulheres que são descendentes das famílias das louceiras. As louças de barro são produzidas nas oficinas das louceiras e a retirada do barro é realizada uma vez, ou no máximo, duas vezes por ano, de forma coletiva por meio de mutirão, o que gera renda sustentável para as mulheres do Distrito do Maruanum (COSTA, 2011).

Sobre as condições de vidas das louceiras, Mafra (2003) destaca que as condições de vida que as mulheres levam são básicas e condizentes com o padrão de vida de pessoas ribeirinhas $^{2}$ da região amazônica. A maior parte das necessidades do grupo de mulheres, como forma de sustento, se encontra em seu redor, seja na floresta nativa, ou nos rios de água doce. Seus hábitos alimentares são, praticamente, os mesmos, nas comunidades em que residem: vivem da caça e da pesca, com uma eventual alimentação produzida fora da comunidade.

As artesãs saem de casa bem cedo para buscar barro entoando cânticos tradicionais. A trajetória é marcada pela alegria. $\mathrm{O}$ artesanato é mais do que um meio de vida para essas mulheres; é um ritual. Inclui canções regionais e muitas superstições. Para tirar o barro, elas só usam as mãos ou pedaços de madeira. Sendo-lhes vedada a utilização de pás ou outros instrumentos cortantes metálicos. É proibido colocar ferro, metal ou alumínio em contato com a terra. Acreditam as louceiras que, se usarem ferro ou outro objeto metálico, o barro deixa de existir.

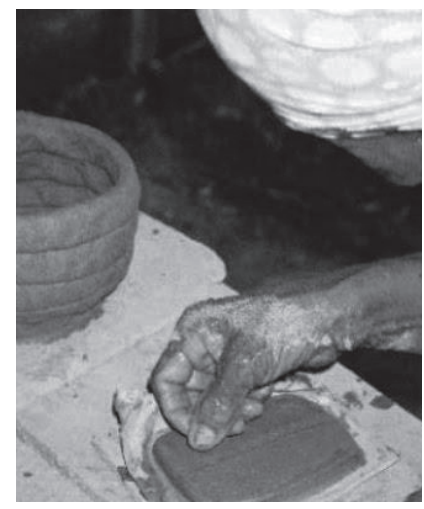

Figura 1- Louceira em atividade Fonte: Kopp (2012).

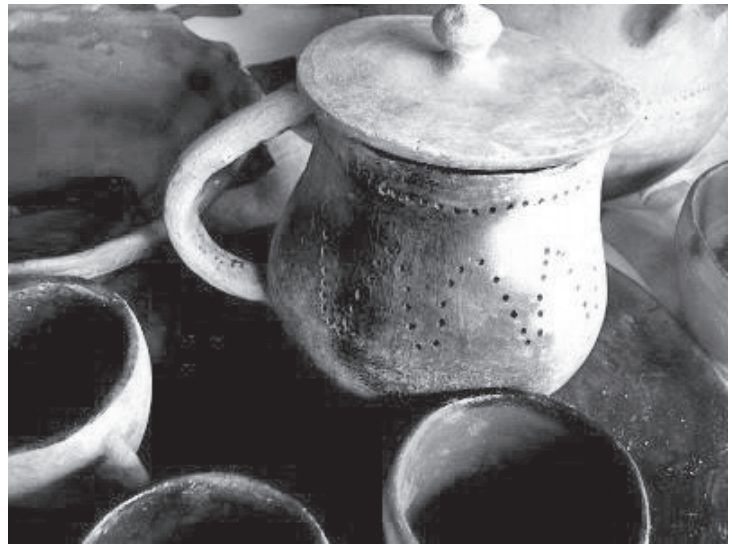

Figura 2 - Louças

Fonte: Kopp (2012).

Depois de cavar o buraco e de retirar o barro, cada artesã faz uma mini caneca ou uma panelinha. As ofertas são para a mãe do barro ou avó do barro. Cada louceira chama de uma forma. De acordo com as louceiras, a Lenda da Mãe do Barro é inspirada em uma crença, segundo a qual, embaixo da fonte de argila do Maruanum reside uma mãe/avó, que fornece o barro e a proteção necessária para a confecção da cerâmica. A entidade é considerada a dona do barreiro, razão pela qual as louceiras "pedem licença" à mesma antes de retirar o barro, retribuindo e deixando oferendas, em forma de pequenas peças produzidas, antes do fechamento do buraco cavado para a extração da argila.

\subsection{A ASSOCIAÇÃO DE MULHERES LOUCEIRAS DO MARUANUM (ALOMA)}

A Associação atualmente é composta por 12 mulheres associadas, que atuam na comunidade do Maruanum e na cidade de Macapá. Para o alcance das informações referentes ao empreendimento entrevistou-se a presidente da ALOMA, de 58 anos de idade, e ainda quatro associadas que trabalham como artesãs há mais de duas décadas.

A escolaridade das louceiras é, em regra, muito baixa, sendo que apenas uma das entrevistadas, encontra-se concluindo o ensino fundamental, por meio da Educação de Jovens 
e Adultos (EJA); o restante declarou-se com ensino fundamental incompleto. No Quadro 1, verifica-se a síntese do perfil das louceiras entrevistadas na ocasião da pesquisa de campo. gilidades das políticas de fomentos, as quais serão descritas a seguir.

\begin{tabular}{|c|l|}
\hline Informação & \multicolumn{1}{|c|}{ Respostas } \\
\hline Idade & Entre 40 a 74 anos. \\
\hline Escolaridade & $\begin{array}{l}\text { Quatro entrevistadas, inclusive a presidente, declararam ter o ensino } \\
\text { fundamental incompleto, e apenas uma entrevistada declarou-se } \\
\text { cursando o ensino médio, por meio do Programa Educacional de } \\
\text { Jovens e Adultos (EJA). }\end{array}$ \\
\hline Profissão / ocupação & $\begin{array}{l}\text { Todas declararam-se artesãs e agricultoras. Apenas uma declarou-se } \\
\text { também parteira tradicional. }\end{array}$ \\
\hline $\begin{array}{c}\text { Quantas pessoas residem na casa } \\
\text { onde mora? }\end{array}$ & Em geral, de 2 a 6 pessoas. \\
\hline $\begin{array}{c}\text { Quantas pessoas trabalham na } \\
\text { residência? }\end{array}$ & $\begin{array}{l}\text { A quatro entrevistadas declararam contribuir para a renda familiar. } \\
\text { Apenas uma declarou-se única responsável pela renda familiar. }\end{array}$ \\
\hline $\begin{array}{c}\text { É beneficiário de programa de } \\
\text { renda mínima }\end{array}$ & $\begin{array}{l}\text { Apenas uma das entrevistadas declarou receber o Programa Estadual } \\
\text { Renda Famíliar e também o Programa Federal Bolsa Família. }\end{array}$ \\
\hline Situação familiar & $\begin{array}{l}\text { Uma única entrevistada declarou ser arrimo de família, as outras } \\
\text { contribuem na renda. }\end{array}$ \\
\hline Renda familiar & $\begin{array}{l}\text { As entrevistadas declararam receber em média renda mensal entre } \\
\text { R\$ 600,00 e R } \$ \text { 900,00. }\end{array}$ \\
\hline
\end{tabular}

Quadro 1 - Perfil social das entrevistadas - ALOMA

Fonte: elaborado pela autora (2016).

A sócia com mais idade, atualmente encontra-se com 74 anos, sendo bastante ativa na produção das cerâmicas, enfatizando que, além do artesanato, também já foi agricultora e trabalhou muito tempo como parteira tradicional, ${ }^{3}$ na comunidade do Maruanum. Atualmente mora em Macapá, onde realiza sua produção e comercialização, sendo que no Maruanum apenas retira o barro junto às outras louceiras.

\subsection{FOMENTOS RECEBIDOS E RESUL- TADOS DO EMPREENDIMENTO}

Com relação aos fomentos à atividade, as louceiras informaram que a Associação possui cadastro em vários órgãos que a têm como economia solidária, como a SENAES, o FAES, a SETE e o SEBRAE, e enfatizam que receberam formação do SEBRAE voltada para as técnicas de gestão, há mais de cinco anos. As entrevistas revelaram aspectos positivos e fra-

\subsubsection{Aspectos positivos das políticas de fomento}

Nos relatos das louceiras, a Secretaria de Estado do Trabalho e Empreendedorismo do Amapá (SETE) atua diretamente no processo de comercialização quando se trata de exposição em feiras por ela organizadas, ou feiras em outros estados, contextos em que viabiliza transporte, e, dependendo do caso, a hospedagem.

Destacaram ainda como aspecto positivo das políticas de fomento a criação da casa de comercialização no Maruanum, viabilizada pela Prefeitura Municipal de Macapá, a qual foi construída entre os anos de 2005 e 2006. Enfatizaram ainda a participação em feiras nacionais e internacionais, com o auxílio do Governo do Estado.

A comercialização, além de ser feita diretamente ao consumidor, é também escoada 
pela Casa do Artesão (vinculada à SETE), sendo que nesta escoação a Casa do Artesão retém $20 \%$ do valor de cada produto como taxa de operacionalidade da comercialização e manutenção da Casa. De acordo com as louceiras, os principais espaços de comercialização são as feiras de exposição.

\subsubsection{Fragilidades das políticas de fo- mento}

As louceiras enfatizaram que não houve nenhum investimento na Associação nos últimos 12 anos, e que o último investimento realizado foi há mais de cinco anos, por meio de organização de mesas para exposição de cerâmicas na Associação, que demandou o investimento de $\mathrm{R} \$ 500,00$ (quinhentos reais). As artesãs informaram ainda que a Associação nunca buscou financiamento ou empréstimo para a dinamização das atividades, quando perguntadas sobre a razão, elas enfatizaram o receio de contrair dívidas.

A casa de comercialização, localizada na comunidade do Maruanum, ficou cerca de quatro anos emprestada para a Polícia Militar do Estado, tendo sido devolvida para a Associação há menos de um ano, de acordo com as louceiras. Estas ressaltam que a casa necessita de reformas, pois encontra-se em estado precário.

Buscou-se compreender também com este estudo os principais avanços e desafios da ALOMA enquanto empreendimento econômico-solidário, dentre os quais destacou-se o seguinte:

\subsubsection{Avanços alcançados pelo empreen- dimento}

Ao serem questionadas sobre os resultados da atividade, as artesãs destacaram que a renda alcançada com a comercialização do artesanato é a principal fonte de recursos das sócias, sendo que as quatro associadas, assim como a presidente da Associação, afirmaram que a renda obtida pela atividade é suficiente para pagar as dívidas, sem, no entanto, restar nenhuma sobra.
Perguntou-se às associadas o que a economia solidária mudou em suas vidas; duas entrevistadas demonstraram falta de compreensão sobre o significado e ideais referentes à economia solidária, mas três delas enfatizaram como alteração positiva a integração do grupo e ainda a visibilidade e o reconhecimento das cerâmicas em todo o Estado do Amapá.

\subsubsection{Desafios a serem enfrentados pelo empreendimento}

A comercialização das louças é feita individualmente por cada louceira; cada uma se incumbe de vender suas cerâmicas, de maneira que não existe divisão de recursos pela Associação, dificultando a possibilidade de avaliar o valor arrecadado anual ou mensalmente. Duas entrevistadas enfatizaram que a Associação não realiza planejamento ou avaliação das atividades da ALOMA. Constata-se, neste sentido, a necessidade de acompanhamento e controle das atividades desenvolvidas, a fim de viabilizar a avaliação sistêmica das atividades.

A renda média mensal informada pelas louceiras com a comercialização das cerâmicas, em geral, é inferior a um salário mínimo, sendo que os instrumentos de trabalho são próprios de cada artesã. Importa mencionar que as artesãs complementam sua renda com a agricultura familiar.

Ao serem questionadas sobre os benefícios e garantias das associadas, as artesãs responderam que não detêm nenhum benefício social, como licenças ou Previdência Social.

Ao serem perguntadas sobre as dificuldades apresentadas nos serviços, as quatro sócias entrevistadas e também a presidente da Associação apontaram as dificuldades para a extração do caripé, que está cada vez mais escasso na região, e ainda destacaram a dificuldade em conseguir transporte para a exposição das cerâmicas em feiras. Esta última questão apresenta-se como uma demanda do Estado, geralmente o transporte das cerâmicas para exposição de feiras é uma ação assumida pela SETE.

Com relação aos desafios a serem en- 
frentados pela ALOMA, as louceiras enfatizam que a gestão atual da Associação necessita ser mais participativa e atuante, de forma a viabilizar a dinamização das atividades.

A produção realizada pelas louceiras, além da dimensão econômica, possui uma importante expressão cultural, uma vez que expressa mitos, saberes e reforça a identidade das artesãs e da comunidade do Maruanum. Verificou-se neste estudo que a atividade já possui uma notória visualização social, tanto por parte do Estado e de organizações não-governamentais, como por parte da sociedade amapaense.

Há de ser destacado que a produção das mulheres louceiras da ALOMA não necessitam de investimentos financeiros elevados, uma vez que o material utilizado é buscado na natureza, seguindo um ritual tradicional. Observa-se ainda que as artesãs, em grande maioria, enfatizaram que com a renda da atividade conseguem pagar suas despesas (as quais não são obtidas em função do empreendimento), mesmo sem sobras, o que viabilizou a análise de que a atividade é satisfatória, mesmo com importantes fomentos a serem realizados para sua dinamização, uma vez que estão conseguindo alcançar renda com a atividade, que em regra, é a maior ou a única fonte de renda das artesãs.

Ao se avaliarem os reflexos da política de fomento à economia solidária junto à ALOMA, observou-se que embora a atividade tenha um notório reconhecimento social e cultural, com relação à atuação governamental e suas formas de fomento, alcançaram-se algumas linhas de reflexão; por ocasião da pesquisa, as louceiras afirmaram que, na atualidade, estas não possuem o acompanhamento e/ou o assessoramento das atividades por parte de qualquer órgão estatal, o que certamente chama a atenção, uma vez que na estrutura de governo há órgãos que deveriam cumprir tal função, como a Secretaria de Estado do Trabalho e Empreendedorismo (SETE) e a Secretaria de Estado da Cultura (SECULT), no âmbito estadual, e ainda a Superintendência Regional de Trabalho e Emprego (SRTE), em âmbito federal. Por outro lado, verificou-se que existe o fomento do Estado no que diz respeito à organização de feiras e transporte das louceiras e suas cerâmicas, assim como a exposição e comercialização da cerâmica produzida no espaço da Casa do Artesão (espaço do Governo do Estado), sendo que sem tais incentivos, as artesãs diminuiriam substancialmente suas vendas, e consequentemente, seus recursos, assim como a visibilidade de seus produtos.

Nesse sentido, conclui-se que, mesmo com aspectos a serem melhorados, podendo ser enfatizados o assessoramento e acompanhamento das atividades, bem como orientação previdenciária, a política de fomento à Associação das Mulheres do Maruanum é relativamente efetiva, uma vez que o Estado tem auxiliado na exposição e comercialização da produção, e ainda subsidiado o transporte que garante a participação das louceiras em feiras, as quais, na grande maioria das vezes, são também organizadas pelo Governo do Estado.

No entanto, há de ser observado que há muito a melhorar com relação à política de fomento, uma vez que o Estado possui um aparato de serviços que tem o potencial de elevar substancialmente a realidade da Associação, seja por meio de cursos de capacitação voltados à gestão de negócios, e a valorização da produção, como técnicas de embalagens, seja com assessoramento e/ou acompanhamento das atividades, e de suporte científico e ambiental para a resolução da problemática do caripé, ou ainda com viabilização de financiamento para investimento na associação e em sua estrutura de trabalho.

Verificou-se também ser a questão previdenciária um grande problema, uma vez que as mulheres do Maruanum não possuem instruções suficientes para acessar direitos disponíveis, como licença-maternidade, ou mesmo aposentadorias, sendo que nenhuma das cinco mulheres entrevistadas, incluindo a presidente da Associação, é contemplada com programas governamentais de renda mínima, mesmo sendo explícitas as privações financeiras em que se encontram.

As cerâmicas das mulheres do Maru- 
anum, como são popularmente conhecidas as louceiras, além de representar uma bela e importante forma de expressão cultural, representam a viabilidade da economia solidária no Estado do Amapá, por meio da valorização dos saberes, do incentivo à cooperação, da preocupação e do respeito com o meio ambiente, e ainda da possibilidade de autogestão por comunidades tradicionais. Essa cultura deve ser valorizada, respeitada e fomentada pelo Estado, e em especial, pelos órgãos executores de políticas públicas de fomento à economia solidária.

\section{CONSIDERAÇÕES FINAIS}

A economia solidária tem adotado importantes contornos em vários países do mundo, afirmando-se como uma alternativa cada vez mais consistente à economia capitalista. No Brasil, as políticas públicas de fomento à economia solidária deram um salto significativo na última década. Um grande fator de contribuição foi a implementação da Secretaria Nacional de Economia Solidária em 2003, criada no início da gestão do Governo Lula.

Este estudo delimitou como campo de estudo a Associação de Mulheres Louceiras do Maruanum (ALOMA), localizada no extremo Norte do Brasil, o Estado do Amapá, onde se buscou identificar os fomentos recebidos pelos órgãos estaduais e seus reflexos no cotidiano das mulheres associadas. Identificou-se a necessidade de reestruturação nos formatos de gestão das políticas de fomento por parte dos órgãos governamentais do Estado do Amapá, os quais deveriam funcionar de forma harmônica e articulada; mas, ao contrário disso, atuam de forma isolada e sem comunicação efetiva entre si, prejudicando a qualidade e a quantidade dos serviços ofertados, o que fora constatado pelas entrevistas realizadas.

Verificou-se que a ALOMA recebe apoio do Estado no que se refere ao transporte para feiras, e ainda para a exposição de suas peças na Casa do Artesão, espaço público vinculado ao Governo. O empreendimento foi também fomentado por meio da viabilização de uma casa na Comunidade do Maruanum, pela prefeitura município de Macapá, para a realização da exposição de suas louças, a qual ficou mais de dois anos cedida para a Polícia Militar do Estado, sem ser utilizada pela Associação.

As louceiras enfatizaram que há muito tempo não recebem nenhuma assistência, orientação ou capacitação por parte de entidades governamentais, ou por parte do Fórum Estadual de Economia Solidária (FAES), ressaltando que poderiam dinamizar o escoamento de seus produtos se tivessem tal suporte. Em função desta realidade, avaliou-se que as políticas de fomento à economia solidária junto à ALOMA são parcialmente efetivas, considerando que as políticas de fomento poderiam ser substancialmente mais amplas, o que certamente elevaria a capacidade de produção, o escoamento dos produtos, e, consequentemente, a renda das louceiras.

Mesmo diante das fragilidades relativas às políticas públicas, constatou-se que a Associação tem sido benéfica às associadas, uma vez que a maioria das louceiras mencionaram que a renda alcançada com a comercialização das cerâmicas tem sido suficiente para o custeio das suas despesas pessoais, as quais, em regra, não estão vinculadas ao empreendimento, uma vez que o investimento para o negócio é muito baixo, em razão de os insumos serem extraídos diretamente da natureza. Algumas louceiras mencionaram ainda a sobra de recursos para outros investimentos, o que leva a crer, em uma análise estritamente financeira, que o empreendimento econômico solidário tem alcançado êxito quanto ao retorno.

Ressalta-se ainda, que as políticas de fomento à economia solidária esbarram numa problemática comum às outras políticas públicas, à falta de articulação e integração entre si, muitas vezes impulsionadas por problemas de comunicação, por falta de percepção da atuação do Estado como um complexo de vários serviços, os quais necessitam funcionar de forma harmônica e equilibrada, e ainda a alta rotatividade de cargos e funções estratégicas.

Restou claro nesta pesquisa que os ór- 
gãos funcionam de maneira desarticulada, e ainda que as políticas são limitadas a cada gestão específica, sendo que a troca dos governantes impede a continuidade das ações. Tal realidade resulta em grandes prejuízos sociais, uma vez que viabiliza a estagnação, e em alguns casos, o retrocesso da ação política.

Após a análise das potencialidades e limitações do empreendimento econômico solidário estudado, alcançou-se a possibilidade de elaboração das seguintes recomendações para a dinamização das atividades e dos resultados do empreendimento: maior articulação e integração entre as políticas de fomento à economia solidária; viabilização de orientação e assessoramento sistemático aos empreendimentos; investimento em orientação previdenciária. $\mathrm{O}$ melhoramento desses pontos viabilizaria a dinamização necessária para que a ALOMA alcance melhores resultados em suas atividades, alterando de forma significativa a qualidade de vida das mulheres associadas.

\section{THE WOMEN'S CERAMIC CRAFTSMANSHIP ASSOCIATION OF MARUANUM (ALOMA): TRADITION AND SOLIDARITY ECONOMY IN THE STATE OF AMAPÁ - AMAZON -BRAZIL}

\section{ABSTRACT}

The solidarity economy is becoming stronger and affirming itself as a viable, sensible and emancipator possibility. In this way, the article aims to analyze the Women's Ceramic Craftsmanship Association of Maruanum (ALOMA), located in the extreme North of the Brazilian Amazon, in the state of Amapá, in order to highlight the main achievements and weaknesses of the development policy of social economy, as well as the main achievements and obstacles faced by the Association. We conducted a case study about Aloma, with Cost-Effectiveness Analysis (CEA), by means of interviews with the president of the Association and other as- sociates, implementing a qualitative research. It's structured in three parts; the first deals with the national solidarity economy policy and its development of strategies for enterprises; the second presents the geographical area of the research, the State of Amapá; the last part analyzes the Association and its profile, and the main results of the development policies and its principal obstacles and advances.

Keywords: Solidarity economy. Public policy. Women's Ceramic Craftsmanship Association of Maruanum.

\section{ASOCIACIÓN DE MUJERES LOCERAS DEL MARUANUM (ALOMA): TRADICIÓN Y ECONOMÍA SOLIDARIA EN EL ESTADO DEL AMAPÁ - AMAZONIA - BRASIL}

\section{RESUMEN}

La economía solidaria viene fortaleciéndose y afirmándose como una posibilidad viable, sensata y emancipadora. Este artículo tiene como objetivo analizar la Asociación de Mujeres Loceras del Maruanum (ALOMA), localizada en el extremo norte de la Amazonia brasileña, en el estado del Amapá, de forma a evidenciar los principales avanzos y fragilidades en la política de fomento a la economía solidaria, así como los principales progresos y trabas enfrentados por la Asociación. Se hizo un estudio de caso de la ALOMA, con Análisis de Costo-Efectividad (ACE), por medio de entrevistas con la presidenta de la Asociación y con otras asociadas, concretizando una investigación cualitativa. El artículo se encuentra estructurado en tres partes, la primera trató de la política nacional de economía solidaria y sus estrategias de fomento a los emprendimientos; la segunda presentó el espacio geográfico de la investigación, el estado del Amapá; y la última parte analizó la Asociación, su perfil, principales resultados de las políticas de fomento y sus principales trabas y avanzos. 
Palabras clave: Economía solidaria. Política Pública. Asociación de Mujeres Loceras del Maruanum.

1 Total de pessoas que trabalharam ou que não trabalharam nos últimos 7 dias, e procuraram trabalho nos últimos 30 dias (Censo Demográfico e a Pesquisa por Amostra Domiciliar - PNAD, do Instituto Brasileiro de Geografia e Estatística - IBGE).

2 Nomenclatura amazônica utilizada para denominar as comunidades ou pessoas que moram às margens dos rios.

3 Atividade comum em comunidades ribeirinhas e cidades pequenas com pouca estrutura de hospitais, na qual mulheres com saberes tradicionais fazem o acompanhamento das gestantes e auxiliam ou realizam o parto, com métodos alternativos aos das clínicas médicas.

\section{REFERÊNCIAS}

AMAPÁ (Estado). Governo do Estado do Amapá. O Estado e sua história: marabaixo o principal evento folclórico do Estado. 2013. Disponível em: <http://ap.gov.br/amapa/ site/paginas/historia/marabaixo.jsp $>$. Acesso em: 20 fev. 2015.

ARAÚJO, Cidália et al. Estudo de caso. 2008. Disponível em: <http://grupo4te.com.sapo.pt/ estudo_caso.pdf $>$. Acesso em: 24 fev. 2015.

BOGDAN, Robert; BIKLEN, Sari. Investigação qualitativa em educação. Porto: Porto Editora, 1994.

COSTA, Célia Souza da. Louceiras do Maruanum em observância aos princípios ambientais: preservação, precaução e função socioambiental da propriedade. Planeta Amazônia - Revista Internacional de Direito Ambiental e Políticas Públicas, Macapá, n. 3, p. 145-152, 2011.

DEPARTAMENTO INTERSINDICAL DE ESTATÍSTICA E ESTUDOS SOCIOECONÔMICOS. Departamento Intersindical de Estatística e Estudos Socioeconômicos. Anuário dos Trabalhadores. São Paulo: DIEESE, 2011.
FRANÇA FILHO, Genauto Carvalho de. Terceiro setor, economia social, economia solidária e economia popular: traçando fronteiras conceituais. Bahia Análise \& Dados, Salvador, v. 2, n. 1, p. 9-19, jun. 2002.

GAIGER, Luiz Inácio. A outra racionalidade da economia solidária: conclusões do primeiro Mapeamento Nacional no Brasil. Revista Crítica de Ciências Sociais, Coimbra, v. 79, p. 5777, dez. 2007.

Antecedentes e expressões atuais da Economia Solidária. Revista Crítica de Ciências Sociais, Coimbra, v. 84, p. 81-99, mar. 2009. Disponível em: <http://base.socioeco. org/docs/rccs_84_luiz_inacio_gaiger.pdf $>$. Acesso em: 25 mar. 2014.

GIL, Antonio Carlos. Como elaborar projetos de pesquisa. 4. ed. São Paulo: Atlas, 2008.

GOERCK, Caroline. Programa de economia solidária em desenvolvimento: sua contribuição para a viabilidade das experiências coletivas de geração de trabalho e renda no Rio Grande do Sul. 2009. 405 f. Tese (Doutorado em Serviço Social) - Pontifícia Universidade Católica do Rio Grande do Sul, Rio Grande do Sul, 2009. Disponível em: <http://www.fbes. org.br/biblioteca22/tese_caroline.pdf $>$. Acesso em: 26 abr. 2013.

INSTITUTO BRASILEIRO DE GEOGRAFIA E ESTATÍSTICA. Censo 2010. 2010. Disponível em: <http://www.ibge.gov.br/estadosat/ perfil.php?sigla=ap>. Acesso em: 20 fev. 2015.

. Estimativas da população residente com data de referência $1^{\circ}$ de julho de 2014. Diretoria de Pesquisas, Coordenação de População e Indicadores Sociais. Diário Oficial da União, Brasília, DF, 28 ago. 2014.

KOPP, Tamires. Artesanato do Maruanum. 
2012. Disponível em: $<\mathrm{http}: / /$ naramazonie. blogspot.com.br/2012/01/artesanato-do-maruanum.html>. Acesso em: 15 fev. 2015.

LECHAT, Noëlle Marie Paule. Economia social, economia solidária, terceiro setor: do que se trata? Civitas - Revista de Ciências Sociais, Porto Alegre, v. 2, n. 1, p. 123-140, jun. 2002.

MAFRA, José Ricardo e Sousa. Artesãs e Louceiras: a forma de vida sob a ótica da Etnomatemática. 2003. Dissertação (Mestrado em Ensino das Ciências e da Matemática) Universidade Federal do Rio Grande do Norte, Natal, 2003.

MAY, Tim. Pesquisa social: questões, métodos e processos. 3. ed. Porto Alegre: Artmed, 2004.

MINAYO, Maria Cecília de Souza (Org.). Pesquisa social: teoria, método e criatividade. Petrópolis: Vozes, 2001.

PORTO, Jadson. Amapá: principais transformações econômicas e institucionais: 1943 a 2000. Macapá: SETEC, 2003.

SANTOS, Aline Mendonça dos. Os dilemas da organização popular do muvimento da econoia solidária no Brasil. Otra Economía, São Leopoldo, v. 8, n. 15, p.196-209, jul./dez. 2014. Disponível em: $<\mathrm{http}: / /$ revistas.unisinos. br/index.php/otraeconomia/article/viewFile/ otra.2014.815.07/4394>. Acesso em: 28 fev. 2014.

SECRETARIA NACIONAL DE ECONOMIA SOLIDÁRIA. Por uma política pública nacional de formação em economia solidária - PPNFES. SENAES/MTE. 2012. Disponível em: <http://www.fbes.org.br/biblioteca22/politica_formacao.pdf $>$. Acesso em: 28 mar. 2014.

Trabalho e Previdência Social. 2013. Disponível em: < http://portal.mte.gov.br/data /files/FF80808148EC2E5E014A394E2F$856 \mathrm{~F} 5 \mathrm{C} /$ Acontece $\% 20$ SENAES $\% 202013 \% 20$ -\%20n34\%20ed\%20especial.pdf>. Acesso em:
28 jul. 2014.

SINGER, Paul. SENAES: uma experiência brasileira de política de economia solidária. In: FRANÇA FILHO, Genauto Carvalho et al. (Org.). Ação pública e economia solidária: uma perspectiva internacional. Porto Alegre: UFRGS, 2006. p. 201-206.

. Os oito primeiros anos da Secretaria Nacional de Economia Solidária. In: LIANZA, Sidney; HENRIQUES, Flávio Chedid (Org.). A economia solidária na América Latina: realidades nacionais e políticas públicas. Rio de Janeiro: Pró Reitoria de Extensão UFRJ, 2012.

. Economia solidária. Entrevista concedida a Paulo de Salles Oliveira. Estudos Avançados, São Paulo, v. 22, n. 62, p. 289-314, jan./ abr. 2008. Disponível em: <http://www.scielo. br/pdf/ea/v22n62/a20v2262.pdf $>$. Acesso em: 27 maio 2014 